\title{
The potential effects of tobacco control in China: projections from the China SimSmoke simulation model
}

\author{
(c) $(1)(9)$ OPEN ACCESS
}

\author{
David Levy professor ${ }^{1}$, Ricardo L Rodríguez-Buño research fellow ${ }^{2}$ visiting fellow in epidemiology \\ and health policy ${ }^{4}$, Teh-Wei Hu professor emeritus ${ }^{5}$, Andrew E Moran Herbert Irving assistant \\ professor of medicine ${ }^{6}$
}

'Lombardi Comprehensive Cancer Center, Population Science, Department of Oncology, Georgetown University, Washington, DC 20007, USA ; ${ }^{2}$ Universidad de Granada, Spain; ${ }^{3 E ́ c o l e ~ d e s ~ H a u t e s ~ E ́ t u d e s ~ e n ~ S a n t e ́ ~ P u b l i q u e, ~ P a r i s, ~ F r a n c e ; ~}{ }^{4}$ Mailman School of Public Health, Columbia University, New York USA; ${ }^{5}$ School of Public Health, University of California at Berkeley, USA; ${ }^{6}$ Division of General Medicine, Columbia University Medical Center, New York, USA

\begin{abstract}
Objective To use a computer simulation model to project the potential impact in China of tobacco control measures on smoking, as recommended by the World Health Organization Framework Convention on Tobacco Control (FCTC), being fully implemented.

Design Modelling study.

Setting China.

Population Males and females aged 15-74 years.

Intervention Incremental impact of more complete implementation of WHO FCTC policies simulated using SimSmoke, a Markov computer simulation model of tobacco smoking prevalence, smoking attributable deaths, and the impact of tobacco control policies. Data on China's adult population, current and former smoking prevalence, initiation and cessation rates, and past policy levels were entered into SimSmoke in order to predict past smoking rates and to project future status quo rates. The model was validated by comparing predicted smoking prevalence with smoking prevalence measured in tobacco surveys from 1996-2010.

Main outcome measures Projected future smoking prevalence and smoking attributable deaths from 2013-50.

Results Status quo tobacco policy simulations projected a decline in smoking prevalence from $51.3 \%$ in 2015 to $46.5 \%$ by 2050 in males and from $2.1 \%$ to $1.3 \%$ in females. Of the individual FCTC recommended tobacco control policies, increasing the tobacco excise tax to $75 \%$ of the retail price was projected to be the most effective, incrementally reducing current smoking compared with the status quo by $12.9 \%$ by 2050 . Complete and simultaneous implementation of all FCTC policies was projected to incrementally reduce smoking by about $40 \%$ relative to the 2050 status quo levels and to prevent approximately 12.8 million smoking attributable deaths and 154 million life years lost by 2050 .
\end{abstract}

Conclusions Complete implementation of WHO FCTC recommended policies would prevent more than 12.8 million smoking attributable deaths in China by 2050. Implementation of FCTC policies would alleviate a substantial portion of the tobacco related health burden that threatens to slow China's extraordinary gains in life expectancy and prosperity.

\section{Introduction}

China is the most populous nation in the world, and with over $50 \%$ of Chinese men smoking ${ }^{1}$ accounts for about a third of the world's smokers. ${ }^{2}$ China is also the world's largest tobacco producer, predominantly by government owned tobacco companies. ${ }^{3}$ Reducing smoking in China would have an enormous public health impact, even on a global scale.

In 2003 China joined the World Health Organization Framework Convention on Tobacco Control (FCTC). The FCTC mandates a comprehensive set of tobacco control policies: surveillance and monitoring of the prevalence of tobacco use, creation of smoke-free environments, treatment of tobacco dependence, taxation on tobacco consumption and other price controls, and enforcement of health warnings on tobacco packages and marketing bans. China increased the tax on tobacco products at the producer and wholesale price level, with an average $11.7 \%$ increase in 2009. The tax increase did not, however, translate to higher retail prices experienced by consumers. ${ }^{4} \mathrm{Of}$ smoke-free environment regulations, only a smoking ban on public transportation has been legislated. China implemented treatment programs for tobacco dependence and to some extent bans on advertising, but these are weakly enforced. Overall, the country profile for China in the WHO 2011 report on the global tobacco 
epidemic identified multiple opportunities to improve implementation of the FCTC. ${ }^{5}$

Studies have estimated the health and economic burden of tobacco related diseases in China, ${ }^{6-10}$ but none have estimated the potential health benefits of complete implementation of the FCTC. Using a version of the SimSmoke tobacco control policy model ${ }^{11-18}$ populated with Chinese national demographic and tobacco exposure data, we projected the potential health impact of a comprehensive tobacco control program in China from 2015-50.

\section{Methods}

\section{The China SimSmoke tobacco policy model}

SimSmoke is a discrete-time first-order Markov process (state-transition) model of the prevalence of tobacco smoking and smoking related mortality that simulates the impact of tobacco control policies. The model begins in a baseline year, with the population divided into current, never, and former smokers by age and sex. The projected population is estimated using fertility and mortality data from the United Nations Population Division, Department of Economic and Social Affairs. ${ }^{19}$ Smoking prevalence evolves with age and sex specific smoking initiation, cessation, and relapse rates. SimSmoke is programmed in Microsoft Excel (Office 2007 version; Microsoft, Redmond, WA, USA).

\section{Tobacco smoking prevalence in China}

We searched the WHO Global InfoBase for studies reporting sex and age specific prevalence of current smoking and ever smoking in China, inclusive of at least ages 15-74 years (see appendix and appendix table 1). ${ }^{20}$ The 1996 national prevalence survey provided estimates of current smoking prevalence for the simulation base year. ${ }^{21}$ We estimated current smoking prevalence for specific ages by linear interpolation between midpoint ages for each 10 year age category.

In the 1996 survey, ever smokers were asked if they had quit. We estimated the prevalence of former smokers in 1996 as the difference between the prevalence of ever smokers and that of current smokers. Those who quit were further asked if they quit for less than six months, six months to one year, one to two years, and two years or more. We used these data to apportion the former smokers to groups representing less than one year, one to two years, and two years or more since quitting. Owing to lack of data for two years or more since quitting, we used US survey percentages (for 3-5 years, 6-10 years, 11-15 years, and $\geq 15$ years) to apportion the former smokers who had quit for two years or more. ${ }^{22}$

Smoking rates evolve through age and sex specific initiation, cessation, and relapse rates. We assumed that cessation, initiation, and relapse rates depend only on current rates and not past behaviors (Markov assumption); that cessation and initiation rates are assumed constant over time, except when changes in policy occur; and that relapse rates are constant over time and unaffected by policies.

Owing to empirical challenges in measuring initiation and cessation among younger smokers and to ensure stability of the model, we measured initiation rates at each age as the difference between the smoking rate at that age year and the rate at the previous age year, determined by year at which smoking rates begin to level off. Because no similar data were provided in the global adult tobacco survey, we relied on the 1996 survey data for initiation and cessation rates. Based on an examination of prevalence data for 1996 and ensuing years, and 1996 data in the 1997 report showing stated ages of initiation, ${ }^{2}$ prevalence rates increased until a specific age. Initiation in the model occurred until age 30 years for men and age 35 years for women. Cessation rates were based on published data in the 1997 report. Based on an examination of 1996 data on smokers who quit in the past year, ${ }^{2}$ we set annual cessation rates in males equal to $2 \%$ for smokers aged 30-65 years and 3\% for those ages 65 years or more. We set the cessation rates in females to $2 \%$. We tracked cessation from age 30 years for males and age 35 years for females. Relapse rates were based on US rates, but the limited information provided on rates in China indicated that similar relapse rates applied. We adjusted first year relapse rates based on model calibration.

To calibrate and validate China SimSmoke predictions from 1996-2010, we used two surveys of tobacco use in China since 1996. The global adult tobacco survey, a cross sectional survey of tobacco use among adults in 16 low and middle income countries sponsored by the US Centers for Disease Control and Prevention and WHO, was used for age and sex specific current tobacco smoking prevalence in 2010 (see appendix). ${ }^{23}$ We used six household survey waves from the multiprovincial China health and nutrition survey (repeated samples of the same households) to estimate the secular trend in active smoking prevalence from 1991 to 2006 (see appendix), with the first nine years used to calibrate the model. ${ }^{24}$

\section{Relative risk of all cause mortality in current and former smokers}

For all cause mortality we use relative risks of 1.35 for male smokers and 1.50 for female smokers aged $35-54$ years, 1.35 for both sexes aged 55-64 years, and 1.30 for both sexes aged 65 years or more. Chinese studies that reported relative risks for all cause mortality in smokers compared with never smokers were in the range $1.19-1.40,{ }^{10}{ }^{25-28}$ with most in the $1.30-1.40$ range. ${ }^{29}$ For former smokers, we assumed relative risks to decline over time at the rate observed in US studies. ${ }^{30}$

\section{Tobacco control policies simulated}

We applied simulated policy effects to current smoking prevalence in the year in which the policy was or could be implemented, and, unless otherwise specified, applied to initiation and cessation rates in future years if the policy was sustained (table $1 \Downarrow$ ). Unless synergies were specified, we reduced the effect of a second policy by [1 minus the effect of the first policy]. Except for the effects of cigarette prices and marketing bans, the model relies on studies of policy effects from high income countries, owing to the lack of studies for low and middle income countries. However, we considered two types of factors that may affect the impact of policies in low and middle income countries relative to high income countries; firstly, the degree of urbanization, which increases the potential reach and therefore effectiveness of policies. During the past 20 years, China's urban population increased from $18 \%$ to $46 \%$ of the total population. ${ }^{31}$ A second factor is a population's baseline level of awareness of tobacco related harms. In countries with lower levels of income and general health awareness and no previous serious tobacco control campaigns, a lower base level of the knowledge of the dangers of smoking and of antismoking attitudes is expected to provide increased potential for the effectiveness of policies.

The SimSmoke China base case (1996-2011) incorporated Chinese policies over the time period on tax policy, legislation on smoke-free environments, mass media anti-tobacco campaigns, bans on tobacco marketing, health warnings, 
cessation of treatment for tobacco dependence, and restrictions on access for youth. China SimSmoke simulated Monitor, Protect, Offer, Warn, Enforce, and Raise (MPOWER) measures ${ }^{32}$ a package of practical steps toward implementation of the FCTC, starting in 2012 and continuing through to 2050 (the last year projected by the model).

\section{Model outcomes}

The two primary outcomes are annual smoking prevalence (percentage), and smoking attributable deaths by age and sex and all causes. From mortality rates, smoking prevalence, and relative risks we calculated the numbers of deaths by age, sex, and smoking status. We multiplied the number of current and former smokers at each age by their respective excess risk and summed the result to obtain total smoking attributable deaths. We compared the effect of implementing WHO

FCTC/MPOWER measures in China starting in 2012, individually and in combination, with the status quo scenario in which tobacco control policies were maintained at 2010 levels. We then calculated the results for smoking prevalence in relative terms (percentage change in smoking prevalence compared with the status quo). The number of deaths averted was calculated as the difference between the number of smoking attributable deaths under the status quo and the number of smoking attributable deaths with policies implemented. Using 2005-10 China specific life expectancies estimated by the United Nations Population Division, ${ }^{33}$ we tabulated life years lost at each age attributed to tobacco from life expectancies for the age at tobacco related death.

\section{Results}

\section{China SimSmoke validation}

Between 1996 and 2010, based on demographic projections, smoking initiation and cessation rates, and tobacco control policy effects, SimSmoke predicted that for ages 15 years or more, the prevalence of age standardized active smoking in males declined from $59.8 \%$ to $52.1 \%$ (see appendix figure 1) The prevalence of active smoking in females declined from $3.5 \%$ to $2.4 \%$. SimSmoke estimates of smoking prevalence in 2010 for ages 15 years or more were similar to the China global adult tobacco survey point estimate $(52.9 \%$ for males; $2.7 \%$ for females) and within the survey's confidence interval boundaries ( $51.7 \%$ to $54.0 \%$ for males; $2.3 \%$ to $3.1 \%$ for females). In addition, SimSmoke projections fit well with active smoking trends in the China health and nutrition survey during 1991-2006. For younger ages (15-34 years), SimSmoke projections followed closely both the global adult tobacco survey 2010 estimate and the China health and nutrition survey trend. For older men and women (35-74 years), SimSmoke predictions mirrored the China health and nutrition survey trend but fell short of prevalence levels from the global adult tobacco survey. However, analyses of more specific age ranges (15-24, 25-44, $45-64$, and $\geq 65$ years) showed that all SimSmoke estimates for prevalence in 2010 fell within the $95 \%$ confidence intervals obtained by the China global adult tobacco survey, except for males aged 45-64 years (SimSmoke 59.1\%; global adult tobacco survey range $60.0-65.8 \%$, see appendix table 2 ).

\section{Projected active smoking prevalence, China, 2015-50}

Projecting the status quo scenario forward, active smoking in males was expected to decrease from $51.3 \%$ in 2015 to $46.5 \%$ by 2050 (table $2 \Downarrow$ ). The prevalence of active smoking in females was projected to decline slightly, from $2.1 \%$ in 2015 to $1.3 \%$ in 2050 (see appendix table 3). In 2015, the estimated number of smoking attributable deaths alone was about one million (932 000 for males and 79000 for females; totals, table $3 \Downarrow$ ) and the estimated life years lost was about 14562000 (13 751000 for males and 811000 for females). In the status quo scenario, annual smoking attributable deaths in males were projected to increase through 2040 to about 1459000 but then decline to slightly less than 1.4 million by 2050 . Projected annual life years lost reached about 17029000 by 2030 and then declined to 15250000 by 2050 . Annual smoking attributable deaths in females were projected to be 49000 in 2040 and 42000 per year in 2050. Under current policies, a total of over 50 million smoking attributable deaths and 626709000 life years lost due to smoking were projected from 2012 to 2050 (table 3).

\section{Impact of implementing FCTC/MPOWER measures}

Relative to the status quo scenario, increasing cigarette taxes to $75 \%$ of the package price was projected to reduce smoking prevalence in relative terms by almost $10 \%$ for both sexes by 2015 (table 2 and appendix table 3). By 2050, smoking prevalence showed a relative reduction of $13 \%$ for males and of $12 \%$ for females in the taxation simulation. With a $75 \%$ tax, about 134000 lives and 1644000 life years would be gained annually by the year 2050 (table 3 ). Summing over the years 2015 to 2050 , approximately 3.5 million deaths would be averted (3 333000 for males and 143000 for females) and 44315000 life years gained (42882000 for males and 1433000 for females) by the tax policy with the benefits continuing to grow in subsequent years.

Though increasing taxes had the largest impact on smoking prevalence, comprehensive smoke-free air laws and a well enforced marketing ban also showed potent and immediate effects. Comprehensive smoke-free air laws were projected to yield an almost $9 \%$ relative reduction in smoking rates by 2015 , increasing to about a $10 \%$ reduction in 2050 , and potentially averting about 3437000 deaths through 2050. A comprehensive marketing ban would reduce smoking prevalence by about $4.0 \%$ and avert 2.15 million deaths by 2050 . A high intensity tobacco control campaign would lead to a $2.5 \%$ relative decline in smoking rates by 2015 and prevent about 1080000 smoking attributable deaths by 2050 . Cessation treatment policies had smaller effects, with cessation policies growing over time to a $4 \%$ relative reduction. Stronger health warnings were projected to yield a relative $2.3 \%$ reduction in smoking rates by 2050 .

When all MPOWER measures were combined, smoking prevalence was initially projected to decrease by about $30 \%$ relative to the status quo in 2015 , and by about $40 \%$ by 2050 . The model projected 494000 (480 000 for males and 14000 for females) fewer smoking attributable deaths by 2050 alone. By 2050, a total of approximately 12.8 million tobacco related deaths (12 274000 for males and 491000 for females) could be averted and 154248000 life years gained (149303000 for males and 4945000 for females) by implementing the complete set of policies.

\section{Discussion}

Using the SimSmoke model calibrated to track with national estimates of smoking prevalence and repeated measures from a multiprovincial survey, we projected that complete implementation of the World Health Organization Framework Convention on Tobacco Control (FCTC)/Monitor, Protect, Offer, Warn, Enforce, and Raise (MPOWER) measures would lead to as much as a $34 \%$ relative reduction in male smoking prevalence 
by 2020 , and a $41.0 \%$ reduction by 2050 (40 years after implementation). Despite the lag time expected between reductions in current smoking and declines in smoking attributable deaths, nearly half a million annual tobacco related deaths could be averted yearly by 2050 . Without complete implementation of WHO FCTC/MPOWER policies, and with other public health factors remaining unchanged, we projected that China will experience an additional 12.8 million preventable smoking related deaths and 154 million life years lost by 2050 . Our projections suggest that the Chinese government's goal of less than $25 \%$ prevalence of active smoking in adults by $2015^{34}$ is only achievable by adding to current tobacco control measures. The year 2025 goal of a relative $30 \%$ reduction in smoking prevalence in people aged 15 years and older targeted by WHO is achievable $\mathrm{e}^{35}$ but only with complete implementation of the WHO FCTC/MPOWER measures.

For many tobacco associated diseases (particularly chronic obstructive pulmonary disease and cancers) the risk related to tobacco use will not usually manifest until 20 years or more. Though we forecast decades into the future, given the "long shadow" cast by tobacco use, a 35 year simulation underestimates the impact of policies. Decreases in deaths related to second hand smoke from the direct impact of smoke-free air regulations and indirect impact of current smoking was not projected, leading to underestimation of the effects on smoking attributable deaths.

Taxation of tobacco products has been an effective means of tobacco control in many nations and was projected to be the most effective policy for China. Our results were broadly consistent with previous reports by one of the authors. ${ }^{46}{ }^{37} \mathrm{We}$ assumed more sensitivity to price changes in younger smokers for several reasons. Teenage and young adult smokers generally earn lower wages, on average smoke less frequently (many less than daily), and are less dependent on tobacco than older smokers, all of which would lead to greater sensitivity to price increases. We also assumed fixed price elasticities over time. We considered an affordability index (price relative to income), but the model fit changes in trend better using a price (adjusted for inflation) index. However, in an economically rapidly developing nation where individual and household incomes have been rising rapidly, price increases may be increasingly more easily tolerated by smokers. In addition, we have assumed that tax increases will be passed along to consumers, leading to an increase in package price from $5.5 \mathrm{CNY}(\$ 0.90 ; £ 0.55 ; € 0.66)$ to $13 \mathrm{CNY}$. A recent tax increase in China was absorbed at the producer (wholesale) level and resulted in no change on cigarette prices for consumers at the point of purchase. ${ }^{48}$ However, if accompanied with other strong tobacco control policies, which reduce future demand for cigarettes and hence increase the incentive to increase current prices, large tax increases are more likely to lead to substantial if not commensurate increases in price. Our results show that multiple policy tools will be needed to substantially reduce the prevalence of smoking.

We projected that smoke-free air laws would be the second best policy, with all other policies simulated leading to more moderate projected effectiveness. As was the case years ago in other nations that evolved through the phases of the tobacco epidemic ${ }^{39}$ cigarette smoking is currently ingrained in Chinese cultural practices. The 2010 global adult tobacco survey found that many Chinese are largely unaware of the adverse health effects of smoking. ${ }^{40}$ For this reason we modified our policy effectiveness assumptions for laws on a smoke-free environment, bans on marketing, and warnings on packaging to account for low awareness of the harms of tobacco in the adult population of China. In particular, the benefits of increasing awareness through health promotion are likely to play an increasingly important role in a country such as China where educational levels are increasing rapidly. Media campaigns can facilitate increased health awareness. The low rates for usage of cessation treatment and advice by health providers on the dangers of smoking also suggest an important role for the health sector, especially if cessation policies are combined with other policies. ${ }^{41}{ }^{42}$ Evidence indicates that many physicians in China smoke, and, given that physicians may be important role models, this practice should be strongly discouraged. ${ }^{43}{ }^{44} \mathrm{We}$ allowed for synergies between media campaigns and other policies but may have underestimated policy effectiveness in assuming that the effect of adding a second policy is reduced if another policy is simultaneously implemented.

\section{Strengths and limitations of this study}

Though it is difficult to directly test the assumptions of China SimSmoke, we did incorporate nationally representative data on smoking prevalence and recent and historical tobacco taxation policies through price. Model validation showed that projections from 1996 to 2010 were consistent with the best available evidence on smoking prevalence levels (from the national surveys) and temporal trends (from the China health and nutrition survey). Inclusion of trend data from the China health and nutrition survey was particularly important for mitigating small variations in the different national surveys that may be due more to differences in survey design and sampling error than to temporal trends. In addition, SimSmoke has performed well in predicting smoking prevalence in over 20 countries, including comparison of model projections with historical effects of past implemented policies in other East Asian and middle income nations with widely different policies. ${ }^{11-18}{ }^{45-48}$ In particular, the Thailand and Korea models closely followed prevalence trends in nations with active tobacco control policies. ${ }^{15} 18$ A SimSmoke analysis of tobacco control policies in Vietnam yielded results similar to those produced by a simulation modeling analysis of tobacco policies in Vietnam by Higashi and colleagues using a different approach. ${ }^{48} 49$

The model validated well, but our China projections should be interpreted with caution because to date evidence on policy intervention for the policies studied in the Chinese context is limited. Of all the policies, taxation has the best evidence base for low and middle income countries. ${ }^{50}$ Evidence on the effectiveness of smoke-free laws on active smoking and media comes almost exclusively from high income countries. ${ }^{51}{ }^{52} \mathrm{In}$ our analysis we incorporated China specific inputs wherever possible, including adjustments for a low population awareness of the harms of tobacco and the degree of urbanization. In other work, we have suggested that the percentage changes in smoking prevalence could vary by as much as $25 \%$ from our best estimate of the effect of changes in tax rates and by as much as $50 \%$ for the effects of other policies. ${ }^{1153}$

Finally, data on cessation and initiation rates were generally not available over time and could not be validated over time. We conducted sensitivity analysis allowing cessation rates and initiation rates to vary by $10 \%$ from the levels used in the model. The resulting changes in smoking prevalence in males projected to 2050 were relatively robust, with ranges of $45.8 \%$ to $47.3 \%$ from variations in initiation rates and of $43.7 \%$ to $49.1 \%$ from variations in cessation rates. Given the low levels of cessation in 1996 and the low rates of advice to quit by healthcare providers and use of cessation treatment, ${ }^{1}$ it will be important to monitor treatment use and cessation and initiation rates in the Chinese population. 


\section{Comparison with other studies}

Our projections on status quo policy smoking attributable deaths for the years 2006 are similar to those estimated by $\mathrm{Gu}$ and colleagues. ${ }^{10}$ Our projections for 2050 are, however, more conservative than Liu and colleague's prediction ${ }^{27}$ of "about three million" smoking attributable deaths annually by that time, perhaps because they assumed no tobacco policy changes, and our status quo case incorporated effects of China's current tobacco control policies.

\section{Conclusions and policy implications}

Our estimates of China's burden of mortality attributable to smoking using the China SimSmoke tobacco policy model suggest that substantial health gains could be made-a $40 \%$ relative reduction in smoking prevalence and almost 13 million smoking attributable deaths averted and more than 154 million life years gained by 2050 - by extending effective public health and clinical interventions to reduce active smoking. Tax policies can play an especially important role, particularly if prices increase with taxes. Consistent with the WHO FCTC, smoke-free air policies, marketing restrictions, health warnings, media campaigns, and cessation treatment policies play an important role. Though smoke-free air laws and marketing bans require enforcement and some costs for implementation (including political capital), a recent report by WHO found that the policies suggested by the FCTC are clearly cost effective using traditional metrics, ${ }^{54}$ a contention that has been reinforced by a study of tobacco control in Vietnam. ${ }^{49}$ Studies of specific policies have also found that smoke-free air laws, ${ }^{55}$ media campaigns, ${ }^{56}{ }^{57}$ and cessation treatment ${ }^{58}$ are cost effective. Tax policy and health warnings, which involve minimal cost, are particularly cost effective.

In the next four decades, China will face over 50 million smoking attributable deaths, the largest absolute burden of smoking related deaths of any nation. Despite that the prevalence of smoking has been decreasing in China for both males and females, the absolute number of smokers will continue to increase for decades. This pattern of prevalence has been predicted globally: the $23.7 \%$ world's overall smoking prevalence for adults in 2010 will continuously decline to $22.7 \%$ by 2020 and to $22.0 \%$ by 2030 , but the number of smokers will increase. ${ }^{2}$ The consequences of inaction are considerable; without the implementation of the complete set of stronger policies, the death and disability legacy of current smoking will endure for decades in China.

We thank the government of the People's Republic of China for conducting the 1996 national prevalence survey and other national tobacco surveys, and the World Health Organization and US Centers for Disease Control for sponsorship of the global adult tobacco survey. This research uses data from the China health and nutrition survey. We thank the National Institute of Nutrition and Food Safety, China Center for Disease Control and Prevention; the Carolina Population Center, University of North Carolina at Chapel Hill; the National Institutes of Health (NIH; R01-HD30880, DK056350, and R01-HD38700); and the Fogarty International Center, $\mathrm{NIH}$, for financial support for the China health and nutrition survey data collection and analysis files since 1989. We thank those parties, the China-Japan Friendship Hospital, and the China Ministry of Health for support for China health and nutrition survey 2009 and future surveys. Lastly, we thank the participants who contributed data to the surveys used for this research. DL received funding from the National Cancer Institute (NCl, 1R01TW009295-01) and Bloomberg Philanthropies to develop the China model and funding was received from the Cancer Intervention and Surveillance Modeling Network (CISNET) of the Division of Cancer Control and Population
Sciences, $\mathrm{NCl}$ (grant UO1-CA97450-02) for general development of the SimSmoke model. T-WH was supported by the US Fogarty International Center of the National Institutes of Health and the National Cancer Institute of the National Institutes of Health (1R01TW009295-01). RLR-B was supported by a European Commission Erasmus Mundus masters program fellowship (Erasmus Mundus category A Europubhealth student scholarship, framework partnership agreement 2006-0047). AEM was supported by a US National Heart, Lung, and Blood Institute career development award (K08 HL089675-01A1).

Contributors: DL and AEM designed the study. DL designed and programmed the SimSmoke tobacco control model. DL and T-WH selected SimSmoke inputs for China. AEM and RLR-B designed the model calibration and validation method and reviewed and selected past Chinese tobacco surveys. AEM and RLR-B conducted original analyses of Global adult tobacco survey and China health and nutrition survey data. RLR-B ran all model simulations and prepared the results and produced the first draft of the manuscript. All authors contributed to writing and reviewing the manuscript. All authors had access to the SimSmoke model, original data, and approved of this manuscript. AEM and DL will act as guarantors.

Funding: This study was supported by Bloomberg Philanthropies; United States National Cancer Institute, National Heart, Lung, and Blood Institute, and Fogarty International Center; the European Commission. The funders took no part in the study design, study conduct, interpretation of the results, or preparation of the manuscript.

Competing interests: All authors have completed the Unified Competing Interest form at www.icmje.org/coi_disclosure.pdf (available on request from the corresponding author) and declare that RLR-B, AEM, T-WH, and DL have support from [the Bloomberg Philanthropies; United States National Cancer Institute, National Heart, Lung, and Blood Institute, and Fogarty International Center; and the European Commission] for the submitted work; have no relationships with any companies that might have an interest in the submitted work in the previous 3 years; their spouses, partners, or children have no financial relationships that may be relevant to the submitted work; and have no non-financial interests that may be relevant to the submitted work.

Ethical approval: Not required; all data analyses were secondary analyses of publicly available, de-identified data.

Data sharing: More details on the model data inputs and other assumptions are provided in a technical appendix. Researchers interested in using or exploring China SimSmoke software or development of a new national SimSmoke software version may contact the corresponding author at d1777@georgetown.edu.

Transparency: The senior author (DL) affirms that the manuscript is an honest, accurate, and transparent account of the study being reported; that no important aspects of the study have been omitted; and that any discrepancies from the study as planned have been explained.

1 Li Q, Hsia J, Yang G. Prevalence of smoking in China in 2010. N Engl J Med 2011;364:2469-70.

2 Mendez D, Alshanqeety O, Warner KE. The potential impact of smoking control policies on future global smoking trends. Tob Control 2013;22:46-51.

3 Yang GH, Ma JM, Liu N, Zhou LN. [Smoking and passive smoking, 2002]. [Chinese]. Zhonqhua Liu Xing Bing Xue Za Zhi 2005;26:77-83.

4 Hu TW, Mao Z, Shi J. Recent tobacco tax rate adjustment and its potential impact on tobacco control in China. Tob Control 2010;19:80-2.

5 World Health Organization. Report on the global tobacco epidemic, 2011: country profile China. www.who.int/tobacco/surveillance/policy/country_profile/chn.pdf.

6 Yang L, Sung HY, Mao Z, Hu TW, Rao K. Economic costs attributable to smoking in China: update and an 8-year comparison, 2000-2008. Tob Control 2011;20:266-72.

7 Lin HH, Murray M, Cohen T, Colijn C, Ezzati M. Effects of smoking and solid-fuel use on COPD, lung cancer, and tuberculosis in China: a time-based, multiple risk factor, modelling study. Lancet 2008;372:1473-83.

8 Zhang J, Ou JX, Bai CX. Tobacco smoking in China: prevalence, disease burden, challenges and future strategies. Respirology 2011;16:1165-72.

9 Wang JB, Jiang $\mathrm{Y}$, Liang $\mathrm{H}$, Li P, Xiao $\mathrm{HJ}$, Ji J, et al. Attributable causes of cancer in China. Ann Oncol 2012;23:2983-9.

10 Gu D, Kelly TN, Wu X, Chen J, Samet JM, Huang JF, et al. Mortality attributable to smoking in China. N Engl J Med 2009;360:150-9.

11 Levy D, Zaloshjna E, Blackman K, Chaloupka F, Fong GT. The role of tobacco control policies in reducing smoking and deaths in the eighteen heavy burden nations: results from the MPOWER SimSmoke Tobacco Control Policy Model. In: Chaloupka FJ, Fong 


\section{What is already known on this topic}

The prevalence of active smoking in Chinese men is among the highest in the world Studies have estimated the mortality and disability burden attributable to smoking in China

They have not, however, estimated how much fully implementing measures recommended by the World Health Organization Framework Convention on Tobacco Control might change future smoking prevalence or prevent tobacco related deaths

\section{What this study adds}

Complete implementation of recommended tobacco control measures in China could lead to a relative reduction of over $40 \%$ in smoking and prevent almost 13 million tobacco related deaths by 2050

GT, Yurekli A, eds. The economics of tobacco and tobacco control. US National Cancer Institute Smoking and Tobacco Control Monograph 21. US Department of Health and Human Services, National Institutes of Health, 2014 (in press).

12 Currie LM, Blackman K, Clancy L, Levy DT. The effect of tobacco control policies on smoking prevalence and smoking-attributable deaths in Ireland using the Ireland SS simulation model. Tob Control 2013;22:e25-32.

13 Levy D, de Almeida LM, Szklo A. The Brazil SimSmoke policy simulation model: the effect of strong tobacco control policies on smoking prevalence and smoking-attributable deaths in a middle income nation. PLOS Med 2012;9:e1001336.

14 Levy DT, Boyle RG, Abrams DB. The role of public policies in reducing smoking: the Minnesota SimSmoke tobacco policy model. Am J Prev Med 2012;43(5 Suppl 3):S179-86.

15 Levy DT, Cho SI, Kim YM, Park S, Suh MK, Kam S. SimSmoke model evaluation of the effect of tobacco control policies in Korea: the unknown success story. Am J Public Health 2010;100:1267-73

16 Levy DT, Nikolayev L, Mumford E. Recent trends in smoking and the role of public policies: results from the SimSmoke tobacco control policy simulation model. Addiction 2005;100:1526-36

17 Nagelhout GE, Levy DT, Blackman K, Currie L, Clancy L, Willemsen MC. The effect of tobacco control policies on smoking prevalence and smoking-attributable deaths. Findings from the Netherlands SimSmoke tobacco control policy simulation model. Addiction 2012;107:407-16

18 Levy DT, Benjakul S, Ross H, Ritthiphakdee B. The role of tobacco control policies in reducing smoking and deaths in a middle income nation: results from the Thailand SimSmoke simulation model. Tob Control 2008:17:53-9.

19 Saffer H. Tobacco advertising and promotion. In: Jha P Chaloupka F, eds. Tobacco control in developing countries. Oxford University Press; 2000:215-36.

20 World Health Organization. Non-communicable disease indicators database. 2012. http //apps.who.int/infobase/.

21 Yang G, Fan L, Tan J, Qi G, Zhang Y, Samet JM, et al. Smoking in China: findings of the 1996 national prevalence survey. JAMA 1999;282:1247-53.

22 US Bureau of the Census. Current population survey, 1992-93: tobacco use supplement file, documentation. 2012. http://riskfactor.cancer.gov/studies/tus-cps/info.html.

23 World Health Organization. Global adult tobacco survey. 2010. www.who.int/tobacco/ surveillance/survey/gats/china/en/index.html.

24 University of North Carolina and Chinese Center for Disease Control and Prevention China health and nutrition survey 1991-2006. 2012. www.cpc.unc.edu/projects/china.

25 Yuan JM, Ross RK, Wang XL, Gao YT, Henderson BE, Yu MC. Morbidity and mortality in relation to cigarette smoking in Shanghai, China: a prospective male cohort study. JAMA 1996;1646-50.

26 Chen ZM, Xu Z, Collins R, Li WX, Peto R. Early health effects of the emerging tobacco epidemic in China. A 16-year prospective study. JAMA 1997;278:1500-4.

27 Liu BQ, Peto R, Chen ZM, Boreham J, Wu YP, Li JY, et al. Emerging tobacco hazard in China: 1. Retrospective proportional mortality study of one million deaths. $B M J$ 1998:317:1411-22.

28 He Y, Chang Q, Huang JY, Jiang Y, Shi QL, Ni B, et al. [Study on mortality, incidence and risk factors of stroke in a cohort of elderly in Xi'an, China] [Chinese]. Zhonghua Liu Xing Bing Xue Za Zhi 2003;24:476-9.

29 Niu SR, Yang GH, Chen ZM, Wang JL, Wang GH, He XZ, et al. Emerging tobacco hazards in China: 2. Early mortality results from a prospective study. BMJ 1998:317:1423-4.

30 Shopland DR, Burns DM, Samet JM, eds. Changes in cigarette-related disease risks and their implication for prevention and control, smoking and tobacco control: National Cancer Institute, National Institutes of Health, 1997

31 Henderson JV. Urbanization in China: policy issues and options. China Economic Research and Advisory Programme. Brown University and National Bureau of Economic Research, 2009.

32 World Health Organization. The MPOWER Strategy. 2012. www.who.int/tobacco/mpower/ publications/en/index.html.

33 United Nations. Population Division Datasets. 2012. www.un.org/esa/population/unpop. $\mathrm{htm}$.

34 General Administration of Quality Supervision, Inspection and Quarantine of the People's Republic of China. China Tobacco Control Programs 2012-2015. 2013. www.miit.gov.cn/ n11293472/n11293832/n12843926/n13917012/15071046.html.

35 World Health Organization. Western Pacific Region Office (WHO-WPRO) global targets on Noncommunicable diseases. 2013. www.wpro.who.int/mediacentre/factsheets/ fs20130311/en/.

36 Hu TW, Mao Z, Shi J, Chen W. Tobacco taxation and its potential impact in China. International Union Against Tuberculosis and Lung Disease, 2008.
37 Hu TW, Mao Z, Shi J, Chen W. The role of taxation in tobacco control and its potential economic impact in China. Tob Control 2010;19:58-64.

$38 \mathrm{Li} \mathrm{Q}, \mathrm{Hu}$ TW, Mao Z, O'Connor RJ, Fong GT, Wu C, et al. When a tax increase fails as a tobacco control policy: the ITC China project evaluation of the 2009 cigarette tax increase in China. Tob Control 2012;21:381.

39 Thun M, Peto R, Boreham J, Lopez AD. Stages of the cigarette epidemic on entering its second century. Tob Control 2012;21:96-101.

40 Center for Disease Control and Prevention. China global adult tobacco survey fact sheet. 12 Aug, 2010. www.who.int/tobacco/surveillance/en_tfi_china_gats_factsheet_2010.pdf.

41 Levy DT, Mabry PL, Graham AL, Orleans CT, Abrams DB. Reaching healthy people 2010 by 2013: a SimSmoke simulation. Am J Prev Med 2010;38(3 Suppl):S373-81.

42 Levy DT, Graham AL, Mabry PL, Abrams DB, Orleans CT. Modeling the impact of smoking-cessation treatment policies on quit rates. Am J Prev Med 2010;38(3 Suppl):S364-72

43 Huang C, Guo C, Yu S, Feng Y, Song J, Eriksen M, Redmon P, Koplan J. Smoking behaviours and cessation services among male physicians in China: evidence from a structural equation model. Tob Control 2013;22(Suppl 2):ii27-33.

44 Jiang $\mathrm{Y}$, Ong MK, Tong EK, Yang Y, Nan Y, Gan Q, et al. Chinese physicians and their smoking knowledge, attitudes, and practices. Am J Prev Med 2007;33:15-22.

45 Levy DT, Huang AT, Currie LM, Clancy L. The benefits from complying with the framework convention on tobacco control: a SimSmoke analysis of 15 European nations. Health Policy Plan 2013; published online 20 Nov.

46 Maslennikova GY, Oganov RG, Boytsov SA, Ross H, Huang AT, Near A, et al. Russia SimSmoke: the long-term effects of tobacco control policies on smoking prevalence and smoking-attributable deaths in Russia. Tob Control 2013; published online 12 Jul.

47 Ferrante D, Levy D, Peruga A, Compton C, Romano E. The role of public policies in reducing smoking prevalence and deaths: the Argentina Tobacco Policy Simulation Model. Rev Panam Salud Publica 2007;21:37-49.

48 Levy DT, Bales S, Lam NT, Nikolayev L. The role of public policies in reducing smoking and deaths caused by smoking in Vietnam: results from the Vietnam tobacco policy simulation model. Soc Sci Med 2006;62:1819-30.

49 Higashi H, Truong KD, Barendregt JJ, Nguyen PK, Vuong ML, Nguyen TT, et al. Cost effectiveness of tobacco control policies in Vietnam: the case of population-level interventions. Appl Health Econ Health Policy 2011;9:183-96.

50 Chaloupka FJ, Hu T, Warner KE, Jacobs R, Yurekli A. The taxation of tobacco products. In: Chaloupka FJ, Jha P, eds. Tobacco control in developing countries. Oxford University Press, 2000.

51 Callinan JE, Clarke A, Doherty K, Kelleher C. Legislative smoking bans for reducing secondhand smoke exposure, smoking prevalence and tobacco consumption. Cochrane Database Syst Rev 2010;4:CD005992.

52 Bala MM, Strzeszynski L, Topor-Madry R, Cahill K. Mass media interventions for smoking cessation in adults. Cochrane Database Syst Rev 2013;6:CD004704.

53 Levy DT, Hyland A, Higbee C, Remer L, Compton C. The role of public policies in reducing smoking prevalence in California: results from the California tobacco policy simulation model. Health Policy 2007;82:167-85

54 World Health Organization. Scaling up action against noncommunicable diseases: how much will it cost? WHO, 2011

55 Mudarri DH. The costs and benefits of smoking restrictions: an assessment of the SmokeFree Environment Act of 1993 (H.R. 3434). Environmental Protection Agency, Office of Radiation and Indoor Air, Indoor Air Division, 1994.

56 Hurley SF, Matthews JP. Cost-effectiveness of the Australian National Tobacco Campaign. Tob Control 2008;17:379-84.

57 Secker-Walker RH, Worden JK, Holland RR, Flynn BS, Detsky AS. A mass media programme to prevent smoking among adolescents: costs and cost effectiveness. Tob Control 1997:6:207-12.

58 Simpson SA, Nonnemaker JM. New York tobacco control program cessation assistance: costs, benefits, and effectiveness. Int J Environ Res Public Health 2013;10:1037-47.

Accepted: 20 January 2014

\section{Cite this as: BMJ 2014;348:g1134}

This is an Open Access article distributed in accordance with the Creative Commons Attribution Non Commercial (CC BY-NC 3.0) license, which permits others to distribute, remix, adapt, build upon this work non-commercially, and license their derivative works on different terms, provided the original work is properly cited and the use is non-commercial. See: http://creativecommons.org/licenses/by-nc/3.0/. 


\section{Tables}

\section{Table 1| Policies, description, and effect sizes of SimSmoke model and policies in China}

\section{Policy}

Tax policy

\section{MPOWER policy simulated} to 2010. Future prices increase with amount of $15-17,-0.30$ ages $18-24,-0.15$ ages cigarette tax in absolute terms of total taxes at $75 \% 25-34,-0.10$ ages $35-64$, and -0.15 ages of retail price

\section{Current policies in China}

Tax rate of $40 \%$ was assumed at retail price. No tax change occurred from 2000-09. China specific price elasticities that vary by age are applied to the tracking period. Using these price elasticities, higher taxes are passed along to consumers, and applied to future active smoking prevalence

\begin{tabular}{lll}
\hline Smoke-free legislation: & & \\
\hline Worksite total ban & Ban in all areas & $9.0 \%$ prevalence reduction effect \\
\hline Restaurant and bar total ban & Ban in all indoor areas of restaurants & $3.0 \%$ effect \\
\hline Other places total ban & $\begin{array}{l}\text { Ban in 3 of 4 (malls, retail stores, public } \\
\text { transportation, and elevators) }\end{array}$ & $1.0 \%$ effect \\
\hline
\end{tabular}

Enforcement and publicity

Government agency is designated to enforce and Effects weakened by as much as $50 \%$ if publicize laws. Publicity effect based on level of no enforcement and publicity tobacco control funding

Smoke-free air laws are limited in China and determined at the municipal level, with no jurisdictions having a work ban (partial or limited) and relatively few private firms having their own bans (those few being international firms). No bans in restaurants,
Mass media campaigns:
Highly publicized campaign Meet requirements for medium level campaign, $3.25 \%$ reduction (doubled when (well funded media and tobacco plus have per capita expenditures over $\$ 0.50$ per accompanied by other policies) control campaign) capita from MPOWER, or evidence from other pubs, and bars; governmental facilities; educational facilities and universities; or healthcare facilities existed by 2010. Overall enforcement of regulation on smoke-free environments has been minimal

Low level media campaign, with no other policies in place sources of strong, well focused media campaign and strong local campaigns

$\begin{array}{ll}\text { Low publicity campaign (low National agency and at least some level of funding } 0.5 \% \text { reduction (doubled when } \\ \text { funded media and tobacco } & \text { and/or employees }>0 \text { from MPOWER, or evidence accompanied by other policies) }\end{array}$ control campaign) from other sources of intermittent media campaign

Marketing bans:

Comprehensive ban

MPOWER: score 4. Ban on direct and indirect $\quad 10.0 \%$ reduction in prevalence, $12.0 \%$ marketing. Ban applied to television, radio, print, reduction in initiation, $6.0 \%$ increase in billboard, instore displays, sponsorships, and free cessation samples

Weak ban MPOWER: score 2. Partial ban on advertising. Ban $2.0 \%$ reduction in prevalence and

A "half way" policy between partial and complete advertising ban, with moderate enforcement (billboard and point of sale tobacco advertising is still allowed in China) to some of television, radio, print, and initiation only billboards

Enforcement and publicity Government agency designated to enforce laws Effects weakened by as much as $50 \%$ if no enforcement

Health warnings:

Complete policy (strong health MPOWER: score 4. Labels are large, bold, and warnings) graphic

$1.0 \%$ reduction in prevalence, $1.0 \%$

Weak health warnings enforced at reduction in initiation, and 5.0\% increase same level over 1996 to 2010 in cessation rate

Minimal policy (weak or minimal MPOWER: score 2. Warning covers less than $30 \% \quad 0.5 \%$ reduction in prevalence and health warning) of package, not bold or graphic initiation rates, $0.5 \%$ increase in cessation rate

Cessation treatment policy Complete availability and reimbursement of $6.75 \%$ reduction in prevalence, $55 \%$ pharmaco and behavioral treatments, "quitlines," increase in cessation and brief interventions

Access restrictions for youth Compliance checks conducted regularly and $30.0 \%$ reduction for age $<16$ years in strongly enforced and publicized publicized, penalties heavy, and bans on vending prevalence and initiation only, $20.0 \%$ machines and self-service
No information found on how long ago cessation treatments became available in China. Model assumed availability started in 2004

No minimum legal purchase age

prevalence and initiation only 


\section{Table 1 (continued)}

MPOWER=simulated Monitor, Protect, Offer, Warn, Enforce, and Raise measures.

*Unless otherwise specified, same percentage effect is applied as percentage reduction in prevalence and initiation rate and percentage increase in cessation rate, and is applied to all ages and both sexes. Effect sizes are shown relative to absence of any policy. 


\begin{tabular}{|c|c|c|c|c|c|c|c|}
\hline Projected smoking prevalence & 1996 & 2010 & 2015 & 2020 & 2030 & 2040 & 2050 \\
\hline \multicolumn{8}{|l|}{ Smoking prevalence (\%) } \\
\hline Status quo policies & 59.8 & 52.3 & 51.3 & 50.4 & 49.0 & 47.5 & 46.5 \\
\hline \multicolumn{8}{|l|}{ Independent policy effects: } \\
\hline Tax at $75 \%$ of retail price & - & - & 46.2 & 45.1 & 43.4 & 41.7 & 40.5 \\
\hline Comprehensive smoke-free air laws & - & - & 46.7 & 45.7 & 44.3 & 42.7 & 41.7 \\
\hline Comprehensive marketing ban & - & - & 49.7 & 48.7 & 47.2 & 45.6 & 44.6 \\
\hline High intensity tobacco control campaign & - & - & 50.0 & 48.9 & 47.5 & 46.0 & 45.0 \\
\hline Strong health warnings & - & - & 50.6 & 49.6 & 48.1 & 46.4 & 45.5 \\
\hline Youth access enforcement & - & - & 51.0 & 49.9 & 48.3 & 46.6 & 45.5 \\
\hline Cessation treatment policies & - & - & 49.9 & 48.8 & 47.1 & 45.5 & 44.6 \\
\hline Combined policy effects & - & - & 35.4 & 33.6 & 31.4 & 29.4 & 28.2 \\
\hline \multicolumn{8}{|c|}{$\%$ change in smoking prevalence from status quo } \\
\hline \multicolumn{8}{|l|}{ Independent policy effects: } \\
\hline Tax at $75 \%$ of retail price & - & - & -10.0 & -10.5 & -11.3 & -12.2 & -12.9 \\
\hline Comprehensive smoke-free air laws & 一 & - & -8.8 & -9.2 & -9.7 & -10.1 & -10.3 \\
\hline Comprehensive marketing ban & 一 & 一 & -3.0 & -3.2 & -3.6 & -3.8 & -4.1 \\
\hline High intensity tobacco control campaign & - & - & -2.6 & -2.8 & -3.0 & -3.2 & -3.3 \\
\hline Strong health warnings & - & - & -1.3 & -1.5 & -1.9 & -2.2 & -2.3 \\
\hline Youth access enforcement & - & 一 & -0.5 & -0.9 & -1.3 & -1.8 & -2.3 \\
\hline Cessation treatment policies & - & - & -2.7 & -3.1 & -3.8 & -4.1 & -4.0 \\
\hline Combined policy effects & - & - & -31.3 & -33.8 & -37.0 & -39.6 & -41.2 \\
\hline
\end{tabular}


Table 3| Smoking attributable deaths and life years lost in males and females aged 15 to 85 years in China, 2015-50, projected by the China SimSmoke model

\begin{tabular}{|c|c|c|c|c|c|c|c|c|}
\hline Policy/years & 1996 & 2012 & 2015 & 2020 & 2030 & 2040 & 2050 & 2012-50 \\
\hline Status quo smoking attributable deaths & 584775 & 956371 & 1011725 & 1115006 & 1351154 & 1459165 & 1399000 & 50343758 \\
\hline \multicolumn{9}{|c|}{$\begin{array}{l}\text { Premature deaths averted (change in smoking attributable } \\
\text { deaths from status quo to policy implemented): }\end{array}$} \\
\hline Tax at $75 \%$ of retail price & - & - & 20525 & 43945 & 110905 & 123413 & 133815 & 3476341 \\
\hline Comprehensive smoke free air laws & - & - & 17698 & 40032 & 110954 & 126329 & 127803 & 3437409 \\
\hline Comprehensive marketing ban & - & - & 11314 & 25307 & 69539 & 78523 & 80421 & 2149873 \\
\hline High intensity tobacco control campaign & - & - & 5120 & 11751 & 34147 & 40536 & 41647 & 1080457 \\
\hline Strong health warnings & - & - & 2304 & 6500 & 21390 & 30218 & 33638 & 59055 \\
\hline Youth access enforcement & - & - & - & - & 63 & 1150 & 2977 & 27186 \\
\hline Cessation treatment policies & - & - & 5221 & 15346 & 51416 & 73327 & 79800 & 1825782 \\
\hline Combined policy effects & - & - & 62059 & 142725 & 400924 & 475113 & 494191 & 12765972 \\
\hline Status quo life years lost & 9737332 & 14044270 & 14561986 & 15522481 & 17028826 & 16738797 & 15250065 & 626709126 \\
\hline \multicolumn{9}{|c|}{$\begin{array}{l}\text { Life years gained (change in life years lost from status quo } \\
\text { to policy implemented): }\end{array}$} \\
\hline Tax at $75 \%$ of retail price & - & - & 281268 & 597457 & 1424838 & 1547173 & 1643770 & 44315184 \\
\hline Comprehensive smoke free air laws & - & - & 263877 & 579045 & 1415029 & 1470649 & 1422007 & 42103017 \\
\hline Comprehensive marketing ban & - & - & 168961 & 368444 & 900977 & 948680 & 948726 & 27138822 \\
\hline High intensity tobacco control campaign & - & - & 76346 & 170000 & 434418 & 466159 & 453706 & 13076991 \\
\hline Strong health warnings & - & - & 33816 & 89147 & 250022 & 310712 & 322030 & 8205264 \\
\hline Youth access enforcement & - & - & 0 & 0 & 2559 & 43226 & 92598 & 949533 \\
\hline Cessation treatment policies & - & - & 76130 & 206643 & 580247 & 705141 & 686079 & 18582968 \\
\hline Combined policy effects & - & - & 903791 & 2015417 & 5040733 & 5490093 & 5479588 & 154247987 \\
\hline
\end{tabular}

Status quo=scenario in which tobacco control policies were maintained at 2010 levels. 